\title{
A crise da psicologia clínica no mundo contemporâneo
}

\author{
The crisis of clinical psychology in today's world
}

\author{
Marco Antônio PORTELA ${ }^{1}$
}

\begin{abstract}
Resumo
O mundo contemporâneo determina novas formas de relação, que afetam a constituição da subjetividade e, por conseguinte, levam ao advento de um novo sujeito. Neste trabalho, fez-se uma análise a fim de compreender quem é o sujeito pós-moderno. No estudo realizado acerca do percurso da psicologia clínica, concluiu-se que suas principais abordagens são individualistas, confirmando o paradigma dominante, ou seja, o paradigma da subjetividade, que levou à exacerbação do individualismo na Pós-Modernidade. Procurou-se fazer uma análise da crise na clínica contemporânea, a fim de compreender suas causas e buscar saídas viáveis para os impasses que se apresentam. Este estudo pautou-se na idéia de que uma nova visão de mundo e do próprio homem está sendo presentemente construída, visão esta que aponta para conceitos como intersubjetividade, dialogia, narrativa, ecologia, entre outros, embora não tenha sido propósito deste trabalho aprofundar estes conceitos.
\end{abstract}

Unitermos:Crise. Pós-modernidade. Psicologia clínica. Subjetividade.

\begin{abstract}
Thetext considersthat thecontemporary world is determining new forms of relationships, which affect theconstitution of subjectivity and, consequently, lead to theadvent of a new typeof individual. An analysis was performed with theaim of understanding exactly who this post-modem individual is. In thestudy carried outconceming the progression of clinical psychology, it isconcluded that itsprincipal approach isindividualist, confiming thedominantparadigm, in otherwords, theparadigm of subjectivity, thathasled to theescalation of individualism in thepost-modern period. The text seeks to analyzethecontemporary clinical crisis in order to understand its causes, and attemptsto find viable solutionsfor the impasses which this crisis presents. The study is predicated upon theidea that a new vision of the world and of man himself is now under construction, a vision which points to concepts such as inter-subjectivity, dialogue, narrative, and ecology, among others. It was not, however, the purpose of this text to explorethese concepts.

Uniterms: Crises. Postmodernism. Clinical psychology. Subjectivity.
\end{abstract}

Este artigo tem como objetivo tecer considerações e reflexões acerca de um tema, de certa forma, constante e familiar à ciência psicológica. Aborda a questão da crise da e na Psicologia Clínica nesta passagem de século, diante dos impasses do paradigma dominante, entre eles, a crise da subjetividade, que não está mais dando conta, por ela mesma, da complexidade do sujeito pós-moderno e de seu contexto histórico social. Esta crise, já delatada no início do século XX por vários psicólogos, hoje tornou-se crônica, pois se agravou e se ampliou sobremaneira. Pode-se dizer, na realidade, que a Psicologia já nasceu dividida e em crise, e que esta é para ela um fator de estruturação. Este artigo faz uma análise ou leitura, em especial, da Psicologia

\footnotetext{
${ }^{1}$ Faculdade de Estudos Administrativos de Minas Gerais, Núcleo de Graduação. R. Cláudo Manoel, 1162, Savassi, 30140-100, Belo Horizonte, MG, Brasil.
} 
Clínica contemporânea. Porém, transita por autores sociólogos e psicólogos sociais, procurando olhar para a clínica de fora; trata-se, portanto, também de uma leitura social da clínica.

Os atuais referenciais teóricos parecem não mais atender às novas demandas de um sujeito que, assim como o mundo, encontra-se em mutação; os velhos modelos e paradigmas já não dão conta de toda sua riqueza e complexidade. Isto coloca o profissional de psicologia diante de uma nova clínica, a ser por ele desvendada. "Utilizamo-nos de nossa linguagem fronteiriça, ajustamos nossos velhos conceitos de modo a fazê-los dizer coisas novas, e nos encontramos em uma situação desconfortável a qual, acredito, deveríamos explicitar" (Melucci, 1996, p.208). Ou seja, tenta-se dizer coisas novas, utilizando uma linguagem velha.

Crise, neste contexto, refere-se à "quebra de uma concepção de mundo. 0 que na consciência coletiva era evidente, agora é posto em discussão" (Boff, 1996, p.16). Equal éa concepção de mundo que se está pondo em xeque? No caso que interessa a este trabalho, tratase do paradigma individualista e da concepção construída e alimentada ao longo de séculos acerca do que é 0 sujeito e a subjetividade. 0 modelo de sociedade que os seres humanos projetaram para si, pelo menos nos últimos 400 anos, estão em crise. "Crise do nosso paradigma dominante, do nosso modelo de relações mais determinante, de nosso sentido de viver preponderante"(Boff, 1996, p.24).

O tema da crise na Psicologia Clínica é extremamente atual, relevante e necessário. A modernidade tardia (Giddens, 2002) tem colocado em xeque estaárea, com seu enfoque predominantemente subjetivo e individualista, o tempo todo. Correntes novas surgem, ou antigas ressurgem das cinzas a cada instante. Pichon-Rivière (1998, p.165) ressaltou como particularidade fundamental da psicologia social ser ela operativa e instrumental, "com características de uma interciência, cujo campo é abordado por uma multiplicidade interdisciplinar (epistemologia convergente) da qual deriva a multiplicidade das técnicas". 0 conceito de epistemologia convergente se encaixa não só para a Psicologia Social, como também para a Psicologia Clínica e, porque não dizer, para toda a Psicologia que, em suas várias linhas, se constituiu em um verdadeiro caleidoscópio interdisciplinar.
Faz-se necessário, neste momento, uma definição sucinta de clínica. 0 termo vem do grego Klíne, que quer dizer cama ou leito, e refere-se às microações. É a arte de olhar, observar e tratar o paciente que está na cama. É o atendimento um por um (Garcia, 1997); no caso da Psicologia, é o contato direto do psicólogo com o paciente. E é, antes de tudo, uma prática que produz um saber. 0 discurso clínico, nesta área, interessa-se pelo sujeito, pela subjetividade. 0 problema que se coloca neste momento é: que sujeito é este de quem a clínica está falando? Ou melhor, que sujeito a teoria da clínica construiu, ao longo do século XX?

A fim de fazer uma análise da clínica no mundo contemporâneo, na primeira parte deste trabalho, procurou-se definir os tempos pós-modernos, bem como o novo sujeito que surge a partir destes novos contextos. Na segunda parte, abordou-se a questão da clínica propriamente dita, os impasses que enfrenta na contemporaneidade e possíveis saídas.

Que a Psicologia está e sempre esteve em crise, isto éclaro.Porque e como mergulhou nessa crise ainda são questões em aberto. Equal a saída para esta situação de crise ininterrupta é ainda mais obscuro. 0 mais provável é que não seja uma única saída, mas várias, talvez tantas quantos sejam os livres pensadores a meditar sobre esta questão. Um novo paradigma em clínica está se construindo ante os olhos dos profissionais da área. 0 que se apresenta neste artigo são apenas reflexões, que visam contribuir para a construção de uma prática clínica mais contextualizada e que atenda às mais prementes necessidades e demandas de um sujeito, em vários aspectos, desnorteado.

\section{A pós-modernidade e seu sujeito}

Pós-modernidade, juntamente com outros termos como mundo contemporâneo, era pós-industrial, sociedade da informação e era do capitalismo tardio são algumas denominações dadas aos tempos atuais, ou seja, os novos contextos a que se referem tais terminologias, iniciados nos anos 60 e evidenciados a partir dos anos 80. Giddens utiliza os termos alta modernidade, ou modernidade tardia, designando-os como a "presente fase de desenvolvimento das instituições modernas, marcada pela radicalização e globalização dos traços básicos da modernidade" 
(Giddens, 2002, p.221).Dequalquerforma, "a necessidade de adjetivos ou prefixos é um sintoma maior da indecisão teórica corrente" (Melucci, 1996, p.199), ou seja, a própria indefinição conceitual acerca da contemporaneidade é uma característica marcante da mesma.

0 mundo pós-moderno se inicia a partir da chamada crise da modernidade, da percepção de que as grandes visões filosóficas, políticas e religiosastípicas da modemidade perderam a legitimidade, a hegemonia e foram, portanto, invalidadas, postas em xeque. Segundo Azevedo (1993, p.30), "O pós-modemo desqualifica esta visão das coisas e esvazia o moderno de seus sonhos de alcance universal".

A pós-modernidade não rompe com o paradigma moderno da subjetividade. Pelo contrário, há uma exacerbação do individualismo rumo ao hiper-individualismo, como diz Lipovetsky (1983, p.116), "o pós-moderno não passa de uma ruptura de superfície... que leva a lógica moderna aos seus limites extremos". 0 saber na modernidade era exclusivo, ou seja, suas teorias, seus conceitos e limites eram estanques, rígidos e não incorporavam novos saberes, enquanto no pós-moderno é inclusivo, ou seja, flexível, permite produzir contrastes e aceita as diferenças.

No modernismo coexistem duas forças, ou duas lógicas: uma burocrática, hierarquizada, disciplinar, rígida, coercitiva, exclusiva, que imperou nos tempos modernos; outra flexível, liberal, igualitária, opcional, permissível, inclusiva, prevalente na pós-modernidade. Pode-se dizer que, na modernidade, predominou a lógica das estruturas burocráticas e que, a partir de meados do século, principalmente dos anos 60 , houve uma inversão e o pêndulo se deslocou, então, para a lógica flexível, hedonista, consumista e imediatista da pós-modernidade.

“A idade pós-moderna, deste ponto de vista, não é de maneira nenhuma a idade paroxística libidinal e pulsional do modernismo; pensaríamos antes o contrário: o tempo pós-moderno é a fase cool e desencantada do modernismo..." (Lipovetsky, 1983, p.105).

Para Giddens (2002, p.27), são três os elementos capazes de explicar o caráter dinâmico e complexo da pós-modernidade: 1) a separação tempo/espaço, que envolve, acima de tudo, o desenvolvimento de uma dimensão vazia de tempo, sendo esta a alavanca principal que também separou o espaço do lugar; 2) os sistemas de desencaixe, que se trata do deslocamento das relações sociais dos contextos locais e sua recombinação através de distâncias indeterminadas do espaço/tempo;3) a reflexividade, que submete a maioria dos aspectos da vida social, pessoal e da relação do sujeito com as coisas e a natureza a uma revisão intensa, à luz de novos conhecimentos ou informações. "A informação especializada, como parte da reflexividade da modernidade, é de uma forma ou de outra constantemente apropriada pelos leigos".

Pode-se dizer que a reflexividade, o desencaixe e a entrada em outra lógica de vivência do tempo e do espaço são características de um mundo globalizado. Para Giddens (2002, p.27): "o conceito de globalização é melhor compreendido como expressando aspectos fundamentais do distanciamento entre tempo eespaço. A globalização diz respeito à interseção entre presença e ausência, ao entrelaçamento de eventos e relações sociais à distância com contextualidades locais".

Desta forma, amizades e relações já não se restringem nem a locais e nem a tempos determinados, mas sim, aos instrumentos de mediação - internet, celular, TV etc. -, que determinam formas diferentes de relações, ou seja, face a face e mediadas (Thompson, 2004).

Melucci (1996), por outro lado, prefere utilizar o termo planetarização para salientar o fato de que 0 homem chegou aos limites, a uma fronteira além da qual não há nem espaço nem tempo: o planeta. Portanto, não há mais espaço que não faça parte do sistema, e nem mesmo do tempo. Segundo o autor, "o que experimentamos agora é um deslocamento e uma planetarização do espaço, de um lado, e uma presentificação do tempo de outro, o que muda radicalmente as categorias em que se baseia a construção da experiência humana"(p.202).

Outro aspecto importante na pós-modernidade é o da produção e utilização da informação como principal recurso mediador e guia das relações: "A maior parte de nossa experiência cotidiana é experiência em enésimo grau, o que significa que ela se situa em contextos que são cada vez mais construídos por informação, transmitidos pela mídia e internalizados pelos indivíduos..." (Melucci, 1996, p.201). 
Portanto, a mídia exerce um papel fundamental na construção do self, principalmente por intermédio do que Giddens (2002) denomina "efeito colagem", ou seja, justaposição de histórias, notícias, curiosidades e itens que nada têm em comum, exceto serem oportunos. 0 efeito colagem faz com que nunca se tenha uma visão completa dos fatos e fenômenos; nunca se fecha completamente uma gestalt, pois só se recebe da mídia recortes, pequenos fragmentos, já devidamente filtrados e preparados para atrair e entreter, antes de chocar e fragmentar. Por outro lado, é humanamente impossível apreender tudo o que acontece no mundo em um dado momento. 0 sujeito tem que se contentar com os fragmentos e recortes, e completar as lacunas com sua experiência, imaginação, e com o sentido compartilhado que constrói em suas relações.

A globalização, com todos os seus efeitos, conduz à tensão dialética entre o local e o global, entre 0 aqui e 0 lá, 0 agora e 0 depois. Antes, podia-se ver 0 global a partir do local; o sujeito pós-moderno vê o local a partir do global. Antes, o local era aqui, hoje pode ser em qualquer lugar. Antes, tinha-se no ancoramento da situação imediata uma referência estável para organização da identidade, o que possibilitava lançar-se no mundo globalizado.

Desta forma, o mundo contemporâneo se encontra diante de um sujeito em conflito, dividido. "A noção de sujeito é extremamente controvertida. Desde o princípio, manifesta-se de forma paradoxal: é simultaneamente evidente e não evidente" (Morin, 1996, p.45). Como diz Touraine (p.75), "a idéia de sujeito não cresce em estufas muito bem protegidas. É planta selvagem". O sujeito pós-moderno, com toda a sua complexidade, não pode ser totalmente contido em nenhuma definição, e escapa a qualquer tentativa de apreensão; está em transformação, em metamorfose, em constituição.

Para Tomka (1997, p.394), "Nosso presente confronta-nos com uma situação nova. Apesar de toda coerência lógica, nosso mundo de experiências se decompõe em fragmentos". Perderam-se os laços com o passado, caíram os mitos e deuses, o futuro se descortina negro, em aberto. As relações com o espaço e o tempo mudaram e se ampliaram; "os horizontes da experiência e da apreensão do mundo começaram a se dilatar ao infinito. As grandes descobertas fizeram de todo o globo terrestre o espaço vital do homem" (Melucci,
1996. p.199); o cidadão está em uma "sociedade planetária", que perdeu sua unidade orgânica, segmentando-se e tornando-se desigual, descontínua, imprevisível e inapreensível. Está fragmentado, cindido entre as diversas arenas em que sua vida se desenrola. 0 espaço privado tem pouca ligação com o espaço público, onde acontece 0 jogo de tensões e pressões sociais. Neste cenário:

o homem modemo vive sob 0 ataque cerrado de experiências carregadas de tensão. 0 mundo em sua mundanidade incondicional, com suas leis próprias, suas diferenças, é por ele experimentado sem uma coesão interior. E dia a dia, ele sente sua incapacidade de apreender suficientemente e de dominar soberanamente a variedade e a dinâmica da realidade que 0 envolve e 0 enlaça. Muitas pessoas não resistem (Tomka, 1997, p.22).

Segundo Hall (2002), há na modernidade tardia a visão de que as identidades modernas estão descentradas, deslocadas, fragmentadas; trata-se da perda de um sentido de si estável. Ora, se a identidade deixa de ser percebida como uma essência substancial, como se pode construir a sensação de permanência do sujeito? A continuidade da identidade está cada vez mais sendo deslocada dos conteúdos para a capacidade pessoal do indivíduo de organizar todas as informações e estímulos que recebe, em um todo coerente para si, e em um processo contínuo.

0 mundo pós-moderno é, como diz Thompson, o mundo da experiência mediada. Para ele, são três as possíveis formas de relação: a face a face; a mediada (cartas, telefones, internet etc); e a quase mediada (TV, jornais, revistas, Internet, rádio etc.), que criam, na pós-modernidade, uma nova forma de relação, na qual os indivíduos podem criar e estabelecer uma forma de intimidade não compartilhada e essencialmente não recíproca (Thompson, 2004).

Cerca de 30 ou 40 anos atrás, o sujeito se constituía basicamente a partir das relações face a face; as relações mediadas e quase mediadas eram apenas formas de relações acessórias e, apesar de o sujeito lançar mão delas, eram pontuais e não tinham maiores influências na constituição da subjetividade. Hoje, no mundo informatizado, globalizado, da internet, do celular, dos satélites, na sociedade da informação, as relações mediadas e quase mediadas ganharam tamanha rele- 
vância que pode-se afirmar, sem medo, que o sujeito se constitui em grande medida a partir delas. As relações mediadas e quase mediadas constituem, portanto, fatores de grande importância para a formação do self.

Como diz Thompson (2004, p.181):

com o desenvolvimento das sociedades modernas, o processo de formação do self se torna mais reflexivo e aberto, no sentido de que os indivíduos dependem cada vez mais dos próprios recursos para construir uma identidade coerente para si mesmos. Ao mesmo tempo, o processo de formação do self é cada vez mais alimentado por materiais simbólicos mediados.

Isto aponta para um self como projeto simbólico, reflexivo e narrativo. No contexto da ordem pós-industrial, o "eu"se torna um projeto reflexivo. Como afirma Giddens (2002, p.37), "Nos ambientes da pós-modernidade, o eu alterado tem que ser explorado e construído como parte de um processo reflexivo de conectar mudança pessoal e social". Desta forma, o self passa a ser visto "principalmente como um produto ou idealização de sistemas simbólicos que o precedem" (Thompson, 2004, p.183), como um projeto simbólico, reflexivo e narrativo, que o indivíduo constrói ativamente a partir de sua história, de sua biografia.

Nunca, na história da humanidade, o local e o global estiveram tão intimamente ligados na formação do self. Cabe ao sujeito construir, em meio ao caleidoscópio de informações que recebe a cada dia em suas relações, uma narrativa coerente e consistente, que amarre todo o cabedal de informações que recebe, criando uma identidade estável e que se sustente na trama histórica que se desenrola no tempo e no espaço.

Ora, hoje, isto se torna extremamente complicado, considerando o grande peso das relações mediadas e quase mediadas na constituição do self. Pois, por meio dessas relações, o sujeito recebe informações fragmentadas, incompletas, quando não distorcidas. Este tipo de relação tem características próp rias. Para muitos indivíduos, a relação quase mediada é apenasuma entre tantas outras formas de interação pelas quais o sujeito intercambia materiais simbólicos, incorporando-os ao seu projeto reflexivo (Thompson, 2004).

Thompson fala da dupla dependência mediada, ou seja, o self se torna mais e mais organizado como projeto reflexivo através do qual ele constrói, na forma de autobiografia narrativa, a própria identidade. Ao mesmo tempo, contudo, os indivíduos se tomam cada vez mais dependentes de um leque de instituições e sistemas sociais que Ihes proporcionam os meios tanto materiais quanto simbólicos - de construção de seus projetos de vida (Thompson, 2004, p.187).

Portanto, a reflexividade, 0 desencaixe, 0 efeito colagem, a relação local global, as relações mediadase quase mediadas com todos os materiais simbólicos disponíveis, dos quais o sujeito hoje lança mão, a fim de realizar seu projeto narrativo, todo estes são fatores que tornam esse sujeito fragmentado e desenraizado.

O sujeito está perdendo a capacidade de dialetizar passado, presente e futuro em uma narrativa coesa. Está cada vez mais desnarrativo, à mercê de momentos pontuais e estanques, em que ele não consegue mais tecer sua trama histórica. Um sujeito imediatista e hedonista, cada vez mais globalizado e mais desmaterializado, tornando-se cada vez mais virtual, etéreo, a cada dia mais distante do outro concreto, da vida concreta, da relação face a face. Está envolto em um casulo protetor (Giddens, 2002), que não só o protege como 0 isola. Tem-se, portanto, 0 advento de um novo sujeito.

Tudo se passa como se o homem pós-moderno se deparasse com sua condição existencial mais radical: a de não possuir um núcleo identitário central estável, contínuo e linear, e sim um vazio que ele tem que preencher, fazendo uso da consciência prática do dia-a-dia. Portanto, não dando mais conta- como fazia em épocas passadas - de tamponar a angústia advinda de sua condição existencial, desenvolve diversas estratégias, a fim de coordenar e ordenar todas as variáveis de sua vida em um todo coerente e contínuo: desde um enrijecimento de suas fronteiras de contato, ou casulo protetor, até a evolução para comportamentos desviantes, patológicos e sintomáticos. Pode-se mesmo dizer que a pós-modernidade inaugura novas formas de adoecimento psíquico.

A crescente disponibilidade dos materiais simbólicos mediados pode não somente enriquecer o processo de formação do self: pode também ter um efeito desorientador.A enorme variedade e multiplicidade de mensagens disponíveis pela mídia pode provocar um tipo de sobrecarga simbólica (Thompson, 2004, p.188). 
Sujeito do cogito, da consciência, do inconsciente, do desejo, da existência; sujeito biológico, cerebral; sujeito da ação e da percepção; sujeito do comportamento; sujeito cognitivo. Sujeito cindido em sua essência, que também se fragmenta em sua existência, passando a sujeito histórico, social, político, epistêmico. Portanto, a partir de meados do século XX, esse sujeito sofre uma fragmentação definitiva.

Um sujeito desiludido, deprimido, ansioso. Um sujeito que rompeu com o passado e com as tradições, mas também não tem um futuro próspero que 0 aguarde. Um sujeito hedonista, imediatista, narcisista, que precisa ter prazer agora, pois poderá não ter tempo depois. Um sujeito também muito mais informado que em eras precedentes, que busca sua independência e autonomia, que defende seus direitos e o das minorias.

As principais polaridades em que se dividiu este sujeito são as contraposições sujeito/indivíduo, autono$\mathrm{mia} /$ heteronomia, autenticidade/inautenticidade e independência/dependência. Autonomia, liberdade e independência são termos comumente relacionados ao sujeito, e heteronomia, alienação e dependência são termos relacionados ao indivíduo.

Mas Renaut (1998, p.63) aponta um equívoco nesta correlação: "... a supervalorização hiperbólica da independência pode levar à afirmação pura e simples do eu enquanto valor imprescritível, não limitável por essência e livre de qualquer normatização". É uma armadilha, um engodo; porém, pode-se dizer que é exatamente o que ocorre hoje, na era do hiper-individualismo: a ênfase exagerada na subjetividade e em um sujeito independente e livre. A sociedade está construindo um sujeito idealizado, desenraizado, que busca a independência e a liberdade a todo custo, a despeito do outro e do mundo, que não passam de utensílios que maneja para ating ir seus fins.

A busca pela independência na modernidade tardia é regra: todos devem ser eles mesmos, originais, autênticos. Ser sujeito hoje é uma exigência e, quando isto ocorre, quando todos em uma sociedade têm que ser eles mesmos, seres únicos, cai-se então na esfera da heteronomia. Portanto, a busca pela autonomia já foi absorvida, assimilada e integrada em uma sociedade essencialmente heterônoma; quanto mais autêntica a pessoa for, mais heterônoma estará sendo.
Porém, neste contexto, autonomia e independência não são sinônimose, como diz Renaut, não existe liberdade natural, sem regras.

A busca da independência está mais para 0 indivíduo que para o sujeito, pois baseia-se na separatividade, na liberdade absoluta e sem regras, implicando na noção de um sujeito auto-fundante, de forma que, no ideal de autonomia e liberdade, incluem-se 0 outro e o mundo. Autonomia, aqui, ganha novos contornos, no dizer de Renaut: "no ideal de autonomia, continuo a ser dependente de normas e leis, com a condição de que eu as aceite livremente" (Renaut, 1998, p.63). Neste contexto, carrega em seu bojo a idéia de interdependência e, portanto, de intersubjetividade - a qual, para Giddens (2002), Hall (2002) e outros, é a âncora da subjetividade. "A idéia de sujeito, precisamente na medida em que ela não se reduz à de indivíduo, mas, ao contrário, implica uma transcendência, uma ultrapassagem da individualidade do eu, comporta nela a intersubjetividade ... nela está incluída por definição a relação com o outro" (Renaut, 1998, p.100).

Portanto, a autonomia está para a interdependência assim como a heteronomia está para a independência. De forma análoga, a subjetividade, como independência, se desliga do conceito de autonomia e se liga à heteronomia. Renaut (1998) também coloca a intersubjetividade como condição da subjetividade, 0 que a clínica não pode mais deixar de considerar: 0 outro vem antes da própria pessoa, a sociedade antes do indivíduo, a filogênese antes da ontogênese, e se há algo imanente ou auto-fundante, este não é o sujeito nem a sociedade, pois ambos constituem uma relação dialética e dialógica, de reciprocidade e mutualidade.

A clínica

A crise da Psicologia é também a crise, sem precedentes, da lógica do sujeito, do paradigma da subjetividade, que deve ser delatada sem medo na busca por uma saída para os impasses, busca esta em que a Psicologia se encontra hoje.

A Psicologia Clínica do século XX, no afã de conhecer quem é este sujeito, exaltou a subjetividade, vendo 0 ambiente como epifenômeno e reforçando 0 paradigma dominante, que se apoiava na idéia de primazia do indivíduo. Portanto, a construção deste, 
feita pela Psicologia Clínica, veio responder a uma demandaideológica, fruto do individualismo moderno. "O individualismo teria impedido a Psicologia de reconhecer os aspectos culturais inerentes à cognição, à experiência subjetiva e à psicopatologia" (Moreira \& Sloan, 2002, p.13).

Em relação ao saber, as mudanças ocorridas na modernidade tardia não o deixam intacto:

as delimitações clássicas dos diversos campos científicos passam ao mesmo tempo por um requestionamento: disciplinas desaparecem, invasões se produzem nas fronteiras das ciências, de onde nascem novos campos. A hierarquia especulativa dos conhecimentos dá lugar a uma rede imanente, por assim dizer, 'rasa', de investigações cujas respectivas fronteiras não cessam de se deslocar (Lyotard, 1986, p.71).

Assiste-se, portanto, ao nascimento de novos campos, híbridos, que surgem nos interstícios dos diversos saberes, cujas fronteiras, nítidas tempos atrás, se dilataram, ou mesmo, diluíram-se e se dissiparam. Cada vez mais os psicólogos e especialistas de diversas áreas estão tendo que lançar mão de outras disciplinas para dar conta de seu objeto de estudo. No interior da própria psicologia, ocorre o mesmo fenômeno, ou seja, os limites até então existentes entre as abordagens clínica e social se dissolveram, e o profissional deve articular o local e o global em um diálogo que dê conta do sujeito pós-moderno.

Quanto à clínica, as matrizes epistemológicas que a sustentavam já não o fazem mais, e as abordagens teóricas estão polissêmicas, dialogando entre si, buscando suas fontes inclusive fora dos domínios da disciplina de origem.

Trata-se do fenômeno da complexidade, em que há uma nova forma de interação entre os saberes, onde se consideram todas as possíveis relações entre o todo e suas partes. Onde o todo é maior que a soma das partes e engloba não só as regularidades e certezas dos saberes, mas leva em conta também o caos, as irregularidades, lacunas e incertezas. A complexidade causauma espécie de curto-circuito nos saberes, tornando possível o relacionamento entre conceitos tão antagônicos que, até então, na modernidade, seriam inarticuláveis, pois seu encontro seria sacrilégio (Neubem, 2004).
Por outro lado, as teorias vigentes em clínica, hoje, chegaram a um ponto de seu desenvolvimento em que surge a tendência a inverter a relação entre teoria e prática. Ao invés de deixar o fenômeno falar por si, a despeito de ameaçar sua construção teórica, tenta-se encaixar o fenômeno no conceito. E o problema é que, hoje, o fenômeno do sujeito pós-moderno já não cabe e nem se sustenta em nenhuma das teorias isoladamente e, na tentativa de não perder terreno, estas calcificam a dinâmica histórica, aberta e factual do fenômeno científico - no caso, o sujeito - para que caiba em seus conceitos.

0 que está em jogo aqui são as próprias teorias e 0 apego da racionalidade científica por modelos. Dupuy (1996) fala do fascínio da ciência pelos modelos, cuja fabricação é universal, mas cujo sentido é invertido nas ciências. Enquanto no senso comum modelo é aquilo que se imita, nas ciências, trata-se o modelo de uma imitação, repetição, reprodução, representação do objeto ou fenômeno estudado.

Arendt (apud Dupuy, 1996) denomina o cientista de Homo Faber, isto porque, antes de tudo, é ele quem concebe e fabrica modelos. Isto Ihe confere um controle sobre os próprios fenômenos. Segundo Arendt, "Controle explicativo e preditivo, em primeiro lugar, graças ao poder da ferramenta matemática ... . Controle do poder criador da analogia, sobretudo ... . Conhecer é produzir um modelo e efetuar sobre ele manipulações ordenadas" (1996, p.23,27).

Mas a pós-modernidade impôs uma nova inversão na relação teoria e prática, devolvendo a primazia para a prática, de onde devem surgir os novos conceitos. Porém, este processo não está sendo tão fácil e linear quanto parece. Os novos campos e as novas demandas, surgidas no mercado de trabalho, estão forçando o psicólogo a sair do consultório e a descobrirnovosfenômenos, que a todo momento questionam e põem em xeque suas teorias.

Pode-se dizer que esta inversão, em que a teoria é que determina o sujeito (ou o fenômeno) e não o contrário, atingiu todas as abordagens em clínica, que se encontram, dentro do enfoque de Vigotski (1998), infladas e com caráter ideológico.

Ao longo do século $X X$, as diversas abordagens estiveram brigando entre si pela hegemonia conceitual. Terapias comportamentais, sugestivas e adaptativas, 
terapias dinâmicas, profundas e analíticas, e também as terapias de caráter compreensivo, todas elas viviam uma relação dialética e não dialógica. Chegaram às vias de uma relação ideológica com a verdade.

Enesta briga interna, os psicólogos clínicos não perceberam que todas estas abordagens, independentemente de serem adaptativas, elaborativas ou sugestivas, são teorias individualistas, que priorizam a subjetividade em detrimento do histórico e do social; por extensão, são teorias que reforçam o paradigma dominante, de olhar para o indivíduo ignorando os diferentes contextos em que está inserido e suprimindo, desta forma, o próprio sujeito.

Portanto, umas das críticas pós-moderna à Psicologia Clínica trata-se da exaltação à subjetividade, em detrimento da dimensão biológica e social. Ao longo do século XX, a clínica se voltou para o estudo do psiquismo, considerando as demais dimensões da existência como epifenômenos, e tendendo, em muitos casos, a encerrar o sujeito em modelos teóricos rígidos e inflexíveis. É preciso definir uma nova relação entre a teoria e seu objeto, uma relação dialógica, na qual a teoria da clínica está sempre pronta a alterar seus conceitos em função das mudanças em seu objeto, o sujeito.

A ênfase na subjetividade levou as teorias da psicologia ao seu caráter abstracionista, ou seja, tornou-as inclinadas a separar o fenômeno psicológico do sujeito que o produz, objetivando estes dois fatos e enfatizando o primeiro em detrimento do segundo, acabando por eliminar definitivamente o sujeito. Porém, a mais importante crítica pós-moderna à clínica é quanto a seu caráter ideológico, por ela reproduzir em suas teorias o paradigma individualista. Existe um paradoxo no paradigma dominante na clínica: ao mesmo tempo em que afirma sobremaneira a subjetividade, ele a exclui em suas teorias e modelos. Na medida em que construiu um arcabouço teórico e conceitual generalista, abstrato e rígido:

... boa parte dos autores clínicos envolvidos nessa discussão promove um questionamento radical quanto à condição epistemológica da teoria (seu uso, suas possibilidades e princípios) na sua relação com a subjetividade e o sentido. Isto porque colocam o desafio sobre até que ponto seria possível construir umateoria sobre a subjetividade sem descaracterizá-la em seus processos ... (Neubem, 2004, p.49).
0 apego aos modelos e às teorias leva também à busca das regularidades, ou seja, do repetitivo, da confirmação dos modelos, ao invés de atentar para osfuros, as falhas, os movimentos desordenados e tudo aquilo que faça as teorias caírem por terra.

Praticamente todas as abordagens têm sua teoria da personalidade, sua teoria do desenvolvimento, sua psicopatologia, e todas em consonância com seus conceitos centraise, de acordo com a ideologia vigente, privilegiam o subjetivo, 0 interno, 0 intrapsíquico, 0 indivíduo (Moreira \& Sloan, 2002). Neubern (2004) mostra como o paradigma dominante determinou o desenvolvimento de um modelo clínico calcado nas noções de interno, essência, indivíduo, universalidade, determinação, natureza, inconsciente, em detrimento de outros modelos, que hoje jáadotam conceitos de transição: “A ausência de uma reflexão epistemológica, ao mesmo tempo em que não permitia a discussão sobre os pressupostos teóricos, alimentava a idéia de que as teorias se legitimavam única e exclusivamente em sua relação com o mundo empírico" (Neubem, 2004, p.26).

Portanto, 0 ideológico está em seu caráter individualista e não social:

a personalidade é uma construção ideológica em dois sentidos. Primeiro, como conceito acadêmico ... surge da conjunção do individualismo liberal e do positivismo das ciências naturais. Segundo, dentro da irracionalidade da ordem social contemporânea, a personalidade (o caráter individual) é sintoma de processos sociais de dominação e opressão (Moreira $\&$ Sloan, 2002, p.77).

0 fator ideológico das teorias surge também quando elas tentam inverter esta equação e colocar o psíquico como anterior ao social e ao biológico. Como se fosse possível ir contra a herança genética ou o mundo onde se nasce, ou mesmo ir contra o fluxo dosacontecimentos sociais no tempo e no espaço.

Dessa forma, ou o sofrimento é atribuído, quanto às suas fontes, ao indivíduo, ou seja, é ele o inadequado, e deve ser submetido aos tratamentos existentes, a psicoterapia entre eles, ou então o sofrimento étomado ontológico e o indivíduo deve conviver com ele. Nos dois casos, a psicologia faz parte da ideologia e impede que os conflitos sociais possam ser vistos como origem do sofrimento (Crochík, 1998, p.3).

Considera-se o "eu" como uma construção frágil, que se dá na interação entre o biológico e o contexto 
histórico-social. Neubern (2004), vêa subjetividade como um "processo sutil que possui várias relações com as dimensões biológicas, sociais e culturais, mas não se esgota ou se explica por alguma delas". Porém, a intersubjetividade e o sujeito do cômputo (Morin, 1996), ou seja, o sujeito histórico-so cial e o sujeito biológico, vêm antes do sujeito psicológico; são estruturas a priori,que sustentam e fundamentam a este último.

Portanto, as propostas pós-modernas em clínica atrelam sua prática não só a uma reflexão teórica, mas também epistemológica, tornando-se aberta e flexível, possibilitando "uma racionalidade específica para a discussão sobre o humano", segundo Neubem (2004, p.188). Racionalidade que rompe com os dogmas das teorias vigentes e busca uma articulação entre diversas abordagens. As teorias devem voltar a se abrir para o frescor do fato ou do fenômeno, como também para as outras teorias. A complexidade permite esta abertura e conduz às mais variadas formas de articulações entre conceitos. É preciso ver as teorias hoje não como antagônicas, mas como complementares.

A incorporação de uma reflexão epistemológica sistemática na psicologia clínica serve como antídoto para a tendência ao abstracionismo, reducionismo, e ao risco deste saber se tornar ideológico.

Eéneste tripé biopsicossocial que se dá a pequena existência do homem. Qualquer abordagem que tenha a pretensão de ser desideologizadora deve considerar em suas análises estas três dimensões da existência. Antes de tudo há um mundo, uma cultura, um contexto histórico; há também um corpo, prematuro, virgem, à espera dos cuidados que lhe possibilitarão constituirum sujeito. Portanto, antes há um corpo e um mundo; antes há o outro, com seu olhar, seu toque, seu corpo, sua palavra, e depois o "eu", o self, com sua persona, seu caráter. Biológico, social e psicológico não se excluem nem se esgotam, mas se complementam e interagem de forma dialética e dialógica.

0 que se tem hoje em clínica não são novos paradigmas, mas o que se pode chamar de paradigmas de transição, que, apesar de ainda afirmarem o modelo dominante, ao mesmo tempo apresentam rupturas em relação a este. As abordagens humanistas-existenciais, em algumas de suas vertentes, são alguns exemplos destes modelos que, apesar de ainda guardar muitos pontos em comum com o paradigma dominante, bus- cam superá-lo pela evolução de seus conceitos ao longo da história.

A produção contemporânea em clínica deu um passo a mais em relação às abordagens mais tradicionais citadas acima, pois prega um retorno ao outro, à relação e ao social. Busca novos conceitos para referendar sua prática, como o de narrativa, dialogia e intersubjetividade.

A abordagem narrativa em terapia visa levar este sujeito fragmentado, desnarrativo, um sujeito que rompeu com seu passado e com as tradições e que também não tem um futuro, a recriar uma história coerente e coesa com seus projetos. Levá-lo a dialetizar novamente passado, presente e futuro. Aprender a dar sentido a suas experiências e encaixá-las de forma coerente em sua cadeia discursiva, dentro de um projeto biográfico. Para Giddens (2002, p.222), narrativa é "estória (ou estórias) por meio da qual a auto-identidade é entendida reflexivamente, tanto pelo indivíduo de que se trata quanto pelos outros".

O conceito de dialogia surgiu do entreda filosofia de Buber (Hycner, 1995). Trata-se da filosofia do diálogo. Significa que o sentido dado pelo sujeito às suas experiências é construído na relação dialógica com o outro e com o mundo, a partir de seus repertórios interpretativos e das pautas interativas em questão. Boff, ao tentar delinear o novo paradigma em construção, dentre vários conceitos, fala também da dialogia, ampliando-a a uma dimensão planetária, ecológica: "há, por fim, a lógica dialógica ou pericorética. Por esta se procura o diálogo em todas as direções e em todos os momentos. Por isto supõe a atitude o mais inclusiva possível e a menos produtora de vítimas. A lógica do universo é dialógica: tudo interage com tudo em todos os pontos e em todas as circustâncias" (Boff, 1996, p.49).

Portanto, a complexidade, a epistemologia e a adoção de conceitos de transição, como os de narrativa e dialogia, apontam para a constituição de um novo paradigma em clínica, e levam a uma visão mais integral do sujeito, na qual as dimensões psicológica, biológica e social interagem mutuamente na construção do self.

\section{Considerações Finais}

A crise da psicologia clínica e do sujeito pós-moderno é, antes de tudo, um sintoma da crise maior 
do paradigma da subjetividade inaugurado na entrada da modernidade. Está acontecendo hoje o declínio do paradigma dominante, que teve seu momento de início e de expansão ao longo dos últimos duzentos anos. 0 hiper-individualismo nada maisé que uma defesa contra o fato de que este já não está respondendo de forma satisfatória às prementes necessidades de um sujeito $\mathrm{e}$ uma humanidade perplexa ante um mundo em destruição e decadência.

Um novo paradigma está se construindo neste momento, e a Psicologia Clínica, no afã de dar conta deste momento, busca também altemativas e caminhos que apontem para o novo. A base construída ao longo do século XX foi fundamental para este novo salto. É a ponte para uma abordagem social em clínica, e para o amadurecimento de conceitos como intersubjetividade, narrativa, dialogia, identidade, ideologia, entre outros.

0 exposto neste trabalho está longe de esgotar todas as possibilidades de interpretar o momento em que a psicologia clínica se encontra hoje. Trata-se apenas de mais uma forma de abordar a questão. E espera-se que possa contribuir, mesmo de forma singela, para a evolução das discussões e para o amadurecimento de nossa ciência, ainda tão nova.

A ampla diversidade de saberes que compõem o campo da Psicologia, que décadas atrás era alvo de críticas, considerada fator negativo para a constituição do campo, é hoje sua grande qualidade e o que lhe dá subsídios para a superação desta crise em que se encontra, e para a contribuição na construção de um novo paradigma em clínica.

Portanto, o caminho para uma nova clínica passa por fazer uma "redução"-epoché-das teorias existentes, voltar novamente para o fenômeno do sujeito, com um novo olhar, deixando que a observação e a prática clínica façam emergir uma nova teoria.

Como se costuma dizer, a clínica é soberana, e qualquer nova teoria ou conceito deve partir da prática, sem deixar, é claro, de considerar o saber instituído, mas sim utilizá-lo como fundamento para o novo, ou 0 instituinte. Na relação entre teoria e prática, esta última passa novamente a ser instituinte da primeira, agora aberta e flexível.

A crise da psicologia apenas reflete a crise do 140 mundo pós-moderno e, por outro lado, a busca e cons- trução de saídas pela Psicologia certamente consistirão também em caminhos para que a sociedade contemporânea encontre novos modelos nos quais possa calcar as relações sociais.

\section{Referências}

Azevedo,M.C.(1993).Não-modemo, modemo e pós-moderno. Revista de Educação AEC, 22 (89), 19-35.

Boff, L. (1996). Ecologia:grito da terra, grito dospobres (2a. ed.). São Paulo: Ática.

Crochík, J. L. (1998). Os desafios atuais do estudo da subjetividade na psicologia. Psicologia USP, 9 (2), 69-85.

Dupuy, J-P. (1996). Nas origens das ciências cognitivas (p p.23-27). São Paulo: UESP.

Garcia, C. (1997). Clínica do social. Dissertação de mestrado não-publicada em Psicologia, Universidade Federal de Minas Gerais, Belo Horizonte.

Giddens, A. (2002). Modernidadeeidentidade. Rio de Janeiro: Jorge Zahar.

Hall, S. (2002). A identidade cultural na pós-modernidade (7a. ed.). Rio de Janeiro: DD\&P.

Hycner, R. (1995). Depessoa a pessoa. São Paulo: Summus.

Lipovetsky, G. (1983). A era do vazio. Lisboa: Relógio D’agua.

Lyotard, J-F. (1986). O pós-moderno. Rio de Janeiro: José Olympio.

Melucci, A. (1996). A experiência individual na sociedade planetária. Revista Lua Nova, 38, 199-221.

Moreira, V., \& Sloan, T. (2002). Personalidade, ideologia e psicopatologia crítica. São Paulo: Escuta.

Morin, E. (1996). A noção de sujeito. In D. Schnitman (Org.), Novosparadigmas:cultura esubjetividade(pp.45-55).Porto Alegre: Artes Médicas.

Neubern, M. (2004). Complexidade de psicologia clínica: desafios epistemológicos. Brasília: Plano.

Pichon-Rivière, E. (1998). O processo grupal.São Paulo:Martins Fontes.

Renaut, A. (1998). 0 indivíduo: reflexões acerca da filosofia do sujeito. Rio de Janeiro: Difel.

Thompson, J. B. (2004). A mídia e a modernidade: uma teoria social da mídia. Petrópolis: Vozes.

Tomka, M. (1997). A fragmentação do mundo das experiências na época moderna. Concilium, 271, 11-27.

Touraine, A. (1998).Poderemosviverjuntos? Petrópolis: Vozes.

Vigotski, L. S. (1998). Teoria e método em psicologia. São Paulo: Martins Fontes.

Recebido em:2/5/2006

Versão final reapresentada em:23/4/2007

Aprovado em:22/5/2007 
